\title{
Utilisation of distally based sural fasciocutaneous flaps in lower extremity reconstruction: a single-centre experience with 88 paediatric patients
}

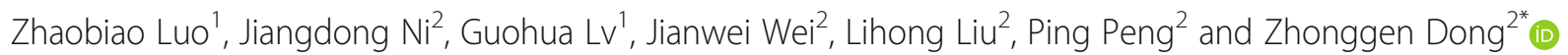

\begin{abstract}
Background: No large series have analysed distally based sural fasciocutaneous (DBSF) flaps in paediatric patients. The aims of this study were to assess the reliability and analyse the potential risk factors for these flaps and to describe complications in the donor site and the functional follow-up results.

Methods: Between June 2002 and November 2017, 88 DBSF flaps were used to reconstruct soft tissue defects in paediatric patients. Potential risk factors, reconstruction outcomes, and complications in the donor site of the flaps were analysed.

Results: Among the 88 flaps, partial necrosis developed in 8 flaps (9.1\%). The partial necrosis rate was significantly higher in flaps with the top edge located in the 9th zone (26.1\%), with a length-width ratio (LWR) $\geq 5: 1$ (28.6\%), and with a dimension of the skin island $\geq 100 \mathrm{~cm}^{2}$ (22.7\%). Partial necrosis did not occur in flaps with a dimension of the skin island $<80.0 \mathrm{~cm}^{2}$ or with a skin-island width $<7.0 \mathrm{~cm}$. The reconstruction outcomes in most paediatric patients were evaluated as "excellent" or "good". The incidence of obvious scarring was higher in the donor site.

Conclusions: Partial necrosis of DBSF flaps will significantly increase when the top edge of the flap is located in the 9th zone, when the LWR of the flap is $\geq 5: 1$, or when the dimension of the skin island is $\geq 100.0 \mathrm{~cm}^{2}$. Flaps with a skin-island width $<7.0 \mathrm{~cm}$ or with a dimension of the skin island $<80 \mathrm{~cm}^{2}$ are relatively safe and reliable.
\end{abstract}

Keywords: Lower extremity, Paediatrics, Soft tissue defect, Sural flap

\section{Introduction}

Reconstruction of soft tissue defects in the distal leg, ankle, and foot is always a delicate problem, especially for paediatric patients. Many types of flaps can be utilised to reconstruct defects in the extremities of paediatric patients, such as local flaps, other pedicled flaps, cross-leg flaps, and free flaps, and each flap has its own respective characteristics and limitations [1-14]. Limited

\footnotetext{
* Correspondence: doctordong@csu.edu.cn

2Department of Orthopaedics, The Second Xiangya Hospital, Central South University, Changsha 410011, People's Republic of China

Full list of author information is available at the end of the article
}

flap size and mobilisation are the drawbacks of local flaps and other pedicled flaps. Cross-leg flaps represent a relatively safer method for paediatric patients, but the legs need to be immobilised with plaster casts or with external fixation, and reoperation is unavoidable to remove the pedicle. Larger defects can be repaired by free flaps, and the donor sites of free flaps can be closed primarily at times, but a tedious surgical procedure is needed with a special microsurgical team, and there is always a risk of re-exploration [13-16].

Since distally based sural fasciocutaneous (DBSF) flaps were reported by Masquelet et al. [17], most authors 
have focused on applying these flaps in adults [18-26], and only a few authors have focused on the reconstruction of soft tissue defects in paediatric patients using these flaps [27-34]. Partial necrosis of DBSF flaps, which was associated with flap factors, was analysed in our previous study [35]. However, a minority of subjects in the study were children, with a majority of adults. There might be differences between the two groups in terms of potential flap risk factors. A specific focus on analysing potential risk factors for DBSF flaps with a considerable sample size for the reconstruction of these defects in paediatric patients is lacking. The aims of this study are to assess reliability and analyse the potential risk factors for DBSF flaps in paediatric patients with a considerable sample size and to describe complications in the donor site and functional follow-up results.

\section{Methods}

All the legal guardians of the paediatric patients provided written informed consent to undergo the operation in combination with possible publication of the treatment and follow-up data. Approval was obtained from the ethics committee of Central South University. The procedures used in this study adhere to the tenets of the Declaration of Helsinki.

\section{Patients}

Between June 2002 and November 2017, the clinical data of 88 DBSF flaps in 88 paediatric patients (age $\leq 12$ years) for the reconstruction of soft tissue defects in the lower extremities were retrospectively reviewed and analysed. DBSF flaps were utilised because of soft tissue defects and exposure of vital structures in the lower extremities.

All the paediatric patients were evaluated preoperatively for their ability to tolerate the operation. If the paediatric patient was cooperative, the location of the peroneal artery perforator was mapped by colour Doppler ultrasonography. Additionally, none of the paediatric patients had a smoking history, peripheral vascular disease (PVD), or chronic medical disease, such as cardiovascular disease, high blood pressure, or diabetes mellitus (DM). The exclusion criteria were as follows: patients who were more than 12 years old; and patients who received cross-leg or proximally based sural fasciocutaneous flaps or perforator pedicled flaps.

The survival of flaps included those that completely and those with marginal necrosis. Flaps with marginal necrosis and those with partial necrosis had necrosis lengths less than $1.0 \mathrm{~cm}$ and more than $1.0 \mathrm{~cm}$, respectively [36]. The potential risk factors for the flaps included patient factors and flap factors (i.e., width of the skin island, length-width ratio [LWR], location of the top edge of the flap, and so on), which were introduced in detail in a previous study [35]. The dimension of the skin island, which has rarely been noted previously, was also analysed in the present study. The shape of the skin island was usually irregular, the length multiplied by the width of the skin island was used to relatively accurately represent the dimension of the skin island, and the index indirectly represented the wound size.

\section{Operative technique}

Radical debridement is one of the most important treatment measures to control infection. The skin island of the DBSF flap should be designed to be approximately $1.0 \mathrm{~cm}$ or $1.5 \mathrm{~cm}$ larger in the periphery than the form of the defect. The proximal edge of the flap should not extend beyond the popliteal fossa, and the lateral edges should not extend beyond the lateral midlines in paediatric patients. The DBSF flaps were harvested with the anterograde-retrograde method, which has been described in detail $[37,38]$. The lesser saphenous vein and the sural nerve must be included as an axis line. To avoid compression of the subcutaneous tunnel and the pedicle, the flap was transferred to the defect through the incised passage. The donor site was closed either primarily or resurfaced with skin grafting. Postoperatively, elevation of the extremity was a useful measure to avoid compression and promote the venous drainage of the flaps. Hyperactivity of the paediatric patients was inevitable. In the hospital bed, strict limiting activities of the paediatric patients was unnecessary, and they were allowed to motion appropriately in the bed, but their parents were informed to look after carefully the patients to avoid the skin-island and fascial pedicle of DBSF flaps compression.

In addition, we evaluated the reconstruction outcomes according to the criteria described by Boyden et al [39]. The criteria included pain, appearance, footwear restrictions, functional restrictions, and patient satisfaction. A patient with "excellent" means that the patient reports no pain, no limitations in recreational or daily activities, and no footwear restrictions, and was satisfied. A patient with "good" means that the patient reports mild occasional pain, limitation of recreational but not daily activities, and no footwear restrictions, and was satisfied, with minor reservations. Complications in the donor site, including pigmentation and scarring, were also evaluated.

\section{Statistical analysis}

Outcomes were analysed utilising the SPSS (version 17.0; SPSS Inc., Chicago, IL) statistical software package. Normal distribution was confirmed using the Kolmogorov-Smirnov test. The continuous variable data in the two groups are presented as the mean \pm standard deviation or mean with range, and analysed by $t$ test or 
Mann-Whitney $U$ test. The categorical variable data are presented as constituent ratios and analysed by the chisquare test, or Fisher's exact test. Multivariate logistic regression analyses were performed. Variables with a $p$ values $<0.1$ in univariate logistic regression analysis were entered into multivariate logistic regression analysis. Results with $p$ values $<0.05$ were considered significant.

\section{Results}

The average time to elevate the flap was $32.6 \pm 6.4 \mathrm{~min}$. Of the 88 DBSF flaps, no flaps with complete necrosis were recorded, and 75 flaps survived uneventfully in one stage. Marginal necrosis occurred in five flaps, of which remanent defects were repaired by suturing in the second stage. Partial necrosis occurred in eight (9.1\%) flaps. Of these eight flaps, only one flap required removal of the necrotic part and was repaired by transferring other regional flap, and the others were repaired by suturing $(n=2)$ or skin grafting $(n=5)$. The defects with the most distal edge located at the metatarsophalangeal joints were successfully covered.

Of the 88 paediatric patients, the average age of 67 males and 21 females was 6.9 years (range, 1-12 years). The main position of the soft tissue defects was the region of the Achilles tendon and heel. The aetiologies of the defects included traumatic $(n=82)$ and nontraumatic causes $(n=6)$; three defects were caused by unstable scars, two were caused by pressure sores on the heel, and one was caused by a tumour. The demographic data of all paediatric patients are shown in Table 1. The constituent ratios of the three indicators did not show any statistically significant differences between the flaps that survived and those with necrosis $(p>0.05)$.

The continuous variable data of the DBSF flaps are shown in Table 2. The length of the skin island, total length of the flap, and dimension of the skin island were significantly greater in the flaps with necrosis $(p<0.05)$.

The categorical variable data of the DBSF flaps are shown in Table 3. When the top edge was located in the 9th zone or when the length-width ratio (LWR) of the flaps was 5:1 or more, the partial necrosis rate of the flaps increased significantly $(p<0.05)$. If the DBSF flap was harvested with a skin-island width $\geq 8.0 \mathrm{~cm}$, the probability of partial necrosis increased, but no statistically significant differences were found between the groups $(p>0.05)$. Among 22 DBSF flaps with skinisland widths $<7.0 \mathrm{~cm}$, no partial necrosis occurred. The dimensions of the skin island in the study ranged from $6.0 \mathrm{~cm} \times 5.0 \mathrm{~cm}$ to $15.0 \mathrm{~cm} \times 11.0 \mathrm{~cm}$, and the average dimension was $80.8 \mathrm{~cm}^{2}$. The partial necrosis rate tended to increase with an increasing dimension of the skin island, especially in flaps with a dimension of the skin island $\geq 100.0 \mathrm{~cm}^{2}$. The partial necrosis rate in the DBSF flaps with a dimension of the skin island $<80.0$ $\mathrm{cm}^{2}(0 \%, 0 / 45)$ was significantly lower than that in the flaps with a dimension of the skin island $\geq 80.0 \mathrm{~cm}^{2}$ $(18.6 \%, 8 / 43)$ (Fisher's exact test, $p=0.002)$. The partial necrosis rate in the DBSF flaps with a dimension of the skin island $\geq 100.0 \mathrm{~cm}^{2}(22.7 \%, 5 / 22)$ was significantly higher than that in the flaps with a dimension of the skin island $<100.0 \mathrm{~cm}^{2}(4.5 \%, 3 / 66)$ (Fisher's exact test, $p=$ $0.021)$.

In the study, independent factors associated with partial necrosis of DBSF flaps included the top-edge location $(p=0.047$, odds ratio [OR]: 6.017, 95\% confidential interval $[\mathrm{CI}]$ : $1.020-35.491)$, dimension of skin island ( $p$ $=0.045$, OR 3.422, 95\% CI 1.029-11.379). Sex, position and cause of defect, site of pivot point, width of the skin island, and LWR were not significant.

All the paediatric patients were followed, with an average period of 19.8 (range, 3-119) months. During the follow-up period, no infections recurred at the recipient

Table 1 Comparison of demographic data between flaps that survived and flaps with partial necrosis

\begin{tabular}{|c|c|c|c|c|}
\hline & $\begin{array}{l}\text { Flaps that survived } \\
(n=80) \\
N(\%)\end{array}$ & $\begin{array}{l}\text { Flaps with partial necrosis } \\
(n=8) \\
N(\%)\end{array}$ & $x^{2}$ & $p$ \\
\hline Sex & & & & $0.390^{*}$ \\
\hline Male & $62(92.5)$ & $5(7.5)$ & & \\
\hline Female & $18(85.7)$ & $3(14.3)$ & & \\
\hline Position of defect & & & 5.368 & 0.068 \\
\hline Pretibial region & $3(100.0)$ & $0(0.0)$ & & \\
\hline Achilles tendon and heel & $50(96.2)$ & $2(3.8)$ & & \\
\hline Dorsum of the foot & $27(81.8)$ & $6(18.2)$ & & \\
\hline Cause of defect & & & & $0.446^{*}$ \\
\hline Traumatic & $75(91.5)$ & $7(8.5)$ & & \\
\hline Non-traumatic & $5(83.3)$ & $1(16.7)$ & & \\
\hline
\end{tabular}


Table 2 Comparisons of continuous variables of flap parameters between flaps that survived and flaps with partial necrosis

\begin{tabular}{|c|c|c|c|c|c|c|}
\hline Parameters* & Range & $\begin{array}{l}\text { Flaps that survived } \\
(n=80)\end{array}$ & $\begin{array}{l}\text { Flaps with partial necrosis } \\
(n=8)\end{array}$ & $U$ & $t$ & $P^{\#}$ \\
\hline Pivot point site (above tip of lateral malleolus) (cm) & $3.5-11.0$ & $6.11 \pm 1.52$ & $6.19 \pm 1.46$ & 306.5 & & $0.839^{\#}$ \\
\hline \multicolumn{7}{|l|}{ Fascial pedicle (cm) } \\
\hline Length & $2.0-9.5$ & $5.68 \pm 1.46$ & $5.06 \pm 2.64$ & 276.5 & & $0.523^{\#}$ \\
\hline Width & $2.5-5.0$ & $3.75 \pm 0.44$ & $3.94 \pm 0.18$ & 244.0 & & $0.205^{\#}$ \\
\hline \multicolumn{7}{|l|}{ Skin island (cm) } \\
\hline Length & $5.0-17.0$ & $9.58 \pm 2.48$ & $12.81 \pm 2.14$ & 91.0 & & $0.001^{\#}$ \\
\hline Width & $4.0-13.0$ & $7.96 \pm 1.85$ & $8.50 \pm 1.28$ & 264.0 & & $0.414^{\#}$ \\
\hline Total length $(\mathrm{cm})$ & $10.0-24.0$ & $15.25 \pm 2.80$ & $17.88 \pm 3.69$ & & 2.468 & $0.016^{\# \#}$ \\
\hline LWR value & $2.5-6.0$ & $4.09 \pm 0.73$ & $4.55 \pm 0.94$ & 235.0 & & $0.217^{\#}$ \\
\hline Dimension of skin island $\left(\mathrm{cm}^{2}\right)$ & $30.0-165.0$ & $78.00 \pm 32.23$ & $108.44 \pm 22.18$ & 127.5 & & $0.005^{\#}$ \\
\hline
\end{tabular}

*The values are expressed as the mean \pm SD

\# The Mann-Whitney $U$ test

\#\#t test

site, three patients experienced ulceration due to poor shoe contact, and seven patients received reoperations because of debulking procedures. The visual gait analysis was nearly normal in most paediatric patients; only three patients had mild claudication, which did not hinder them from rapid walking, running, or participating in sports. In our series, no patients complained of insensitivity on the lateral aspect of the foot caused by the sacrificed sural nerve. The reconstruction outcomes of the paediatric patients were evaluated as "excellent" in 72 cases (Figs. 1 and 2), "good" in 14 cases, and "fair" in 2 cases. No patients were evaluated with "poor" outcomes. All the wounds of the donor site healed successfully, and no cases of infection or skin necrosis occurred at the donor site. The donor site was closed primarily in only five cases. Pigmentation of the donor site occurred in a few patients, but obvious scarring of the donor site was observed in the majority of paediatric patients. Scar contracture of the donor site did not affect the motion of the knee in the paediatric patients.

\section{Discussion}

In DBSF flaps, flap viability-related complications, such as partial or complete necrosis, remain a concern.

Table 3 Comparisons of the constituent ratio of categorical variable data between flaps that survived and flaps with partial necrosis

\begin{tabular}{|c|c|c|c|c|}
\hline & $\begin{array}{l}\text { Flaps that survived } \\
(n=80) \\
N(\%)\end{array}$ & $\begin{array}{l}\text { Flaps with partial necrosis } \\
(n=8) \\
N(\%)\end{array}$ & $x^{2}$ & $p$ \\
\hline Pivot point (above tip of lateral malleolus) & & & & $0.678^{*}$ \\
\hline$\leq 6 \mathrm{~cm}$ & $59(92.2)$ & $5(7.8)$ & & \\
\hline$>6 \mathrm{~cm}$ & $21(87.5)$ & $3(12.5)$ & & \\
\hline Top-edge location & & & & $0.004^{*}$ \\
\hline The 8th zone or lower zone & $63(96.9)$ & $2(3.1)$ & & \\
\hline The 9th zone & $17(73.9)$ & $6(26.1)$ & & \\
\hline Length-width ratio & & & & $0.020^{*}$ \\
\hline $2.50 \leq \mathrm{LWR}<5: 1$ & 70 (94.6) & $4(5.4)$ & & \\
\hline $5 \leq \mathrm{LWR} \leq 6: 1$ & $10(71.4)$ & $4(28.6)$ & & \\
\hline Width of the skin island & & & & $0.459^{*}$ \\
\hline $4.0 \mathrm{~cm} \leq$ width $<8.0 \mathrm{~cm}$ & 35 (94.6) & $2(5.4)$ & & \\
\hline $8.0 \mathrm{~cm} \leq$ width $\leq 13.0 \mathrm{~cm}$ & $45(88.2)$ & $6(11.8)$ & & \\
\hline Dimension of skin island & & & 12.809 & 0.002 \\
\hline$<80.0 \mathrm{~cm}^{2}$ & $45(100.0)$ & $0(0.0)$ & & \\
\hline $80.0 \mathrm{~cm}^{2} \leq$ dimension $<100.0 \mathrm{~cm}^{2}$ & $18(85.7)$ & $3(14.3)$ & & \\
\hline$\geq 100.0 \mathrm{~cm}^{2}$ & $17(77.3)$ & $5(22.7)$ & & \\
\hline
\end{tabular}



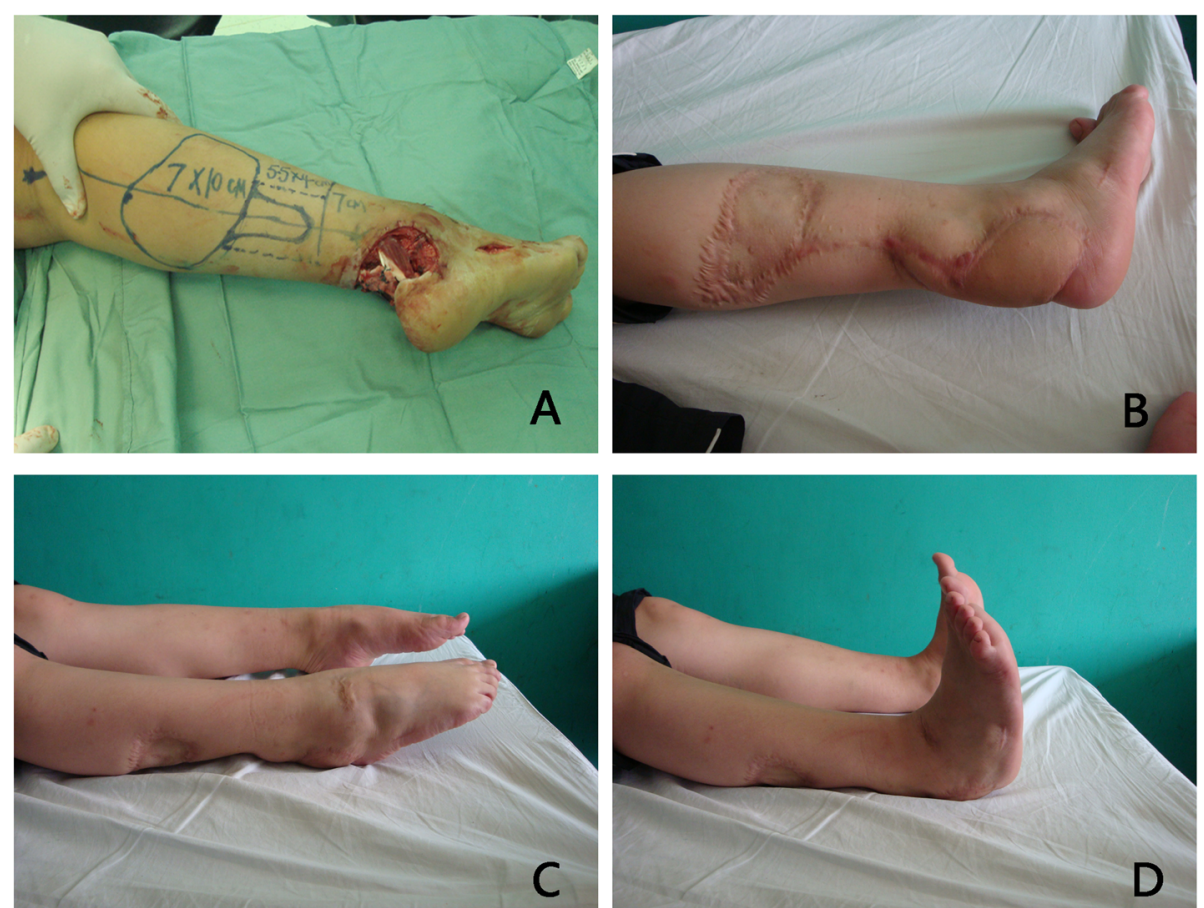

Fig. 1 A 3-year-old girl suffered from a traumatic soft tissue defect in the Achilles tendon area. a Defect appearance after debridement, and a distally based sural fasciocutaneous flap was designed. $\mathbf{b}$ Appearance outcomes of the flap and donor site 21 months postoperatively. Pigmentation of the donor site did not occur, but obvious scarring of the donor site was observed. c, d "Excellent" reconstruction outcomes 21 months postoperatively
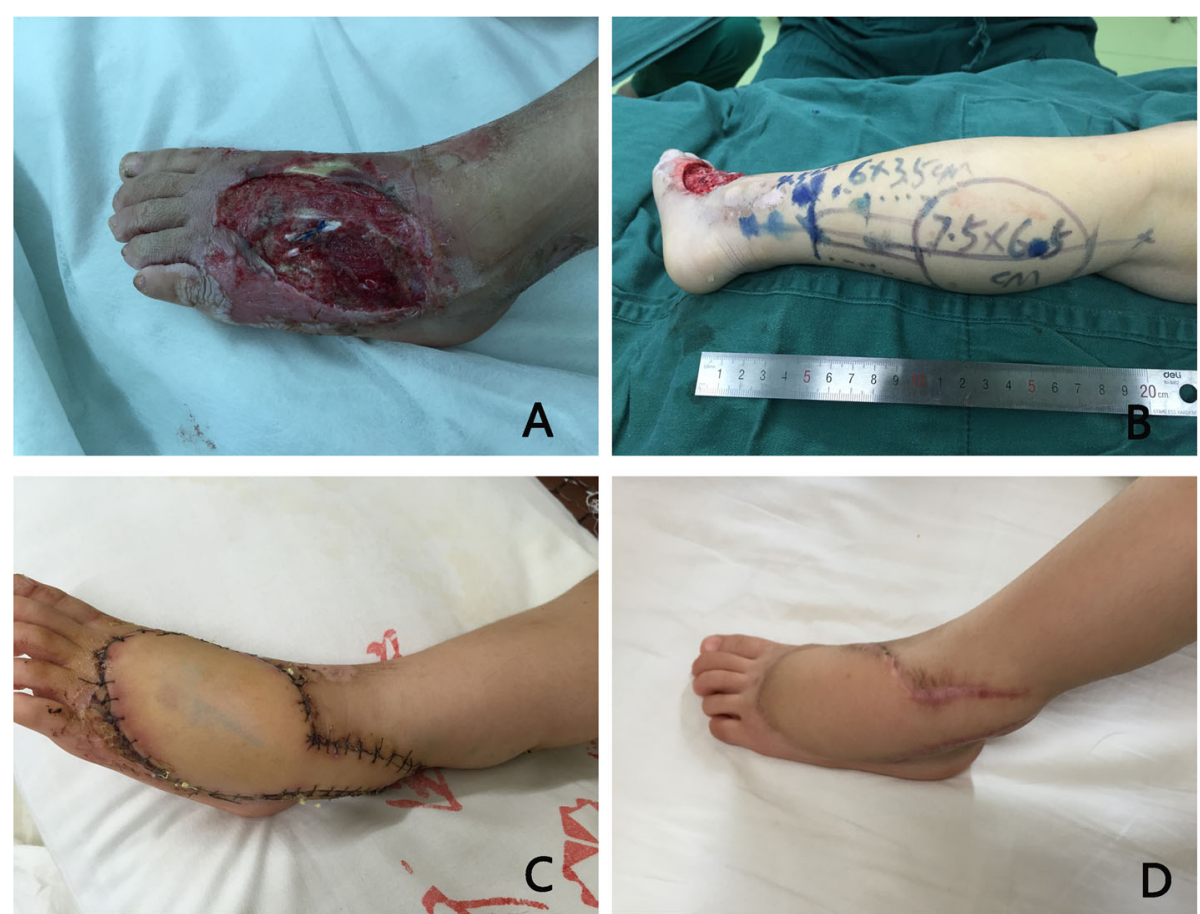

Fig. 2 A 3-year-old girl suffered from a traumatic soft tissue defect in the dorsum area of the left foot. a Preoperative appearance of defect. b. A distally based sural fasciocutaneous flap was designed. c Appearance outcomes of the flap two weeks postoperatively, the flap survived uneventfully. $\mathbf{d}$ Appearance outcomes of the flap 9 months postoperatively 
During the last decade or two, a few other authors reported the use of DBSF flaps in paediatric patients, and various necrosis rates were reported as follows: $0.0 \%(0 /$ 32) by Liu et al. [32], 5.0\% (1/20) by Koladi et al. [28], $5.6 \%(2 / 36)$ by Zheng et al. [33], $12.5 \%(2 / 16)$ by Mahmood et al. [30], 12.5\% (2/16) by Vergara-Amador et al. [29], and $20.0 \%(4 / 20)$ by Grandjean et al [34]. In the present study, the partial necrosis rate of the DBSF flaps was $9.1 \%(8 / 88)$. Seven remanent defects were covered successfully by using simple treatments. Only one remanent defect was covered successfully by transferring a regional flap. The average time to elevate the flap was approximately $30 \mathrm{~min}$. The coverage range of the DBSF flaps in the study was from the lower leg to the metatarsophalangeal joints. The results of the study displayed the reliability, convenience, and large coverage range of DBSF flaps in paediatric patients.

Age, DM, PVD, and smoking are associated with flap failure [20, 26, 40]. However, all the patients in the study were paediatric patients, and none had histories of DM, PVD, or smoking. The probability of partial necrosis in DBSF flaps is associated with the width of the skin island, LWR, and location of the top edge [35]. In the present study, the potential risk factors for DBSF flaps were analysed emphatically. In the present study, when the top edge of DBSF flap was located in the 9th zone, the partial necrosis rate of the flaps significantly increased. This was similar to a previous paper [35]. The LWR of DBSF flap was not significant in the multivariate logistic regression analysis, but in the univariate analysis, when the LWR of DBSF flap was 5:1 or more, the partial necrosis rate of the flaps significantly increased. As introduced in the previous article [35], we considered that LWR $\geq 5: 1$ is also a risk factor for DBSF flap in the paediatric patients. However, a skin island width $\geq 8.0 \mathrm{~cm}$ was not a risk factor for DBSF flaps in paediatric patients. There was no partial necrosis of flaps when the width of the skin island was $<7.0 \mathrm{~cm}$, although the maximum width of the skin island was $13.0 \mathrm{~cm}$, and the flap successfully covered the defect in one stage. The results suggested that DBSF flaps with a width of the skin island $<7.0 \mathrm{~cm}$ are safer and more reliable for paediatric patients. According to Yang and Morris's anatomic and angiographic study, the maximum width of the potential territory of the reversed sural island flap was $7.0 \mathrm{~cm}$ [18]. This may explain why the DBSF flap with a width of the skin island < $7.0 \mathrm{~cm}$ was safer and more reliable.

How large a flap can be for safe elevation in paediatric patients is controversial. Shea et al. reported that the wound surface area was a risk factor for flap complications in adult patients; flap procedures performed on larger wounds (size $>200 \mathrm{~cm}^{2}$ ) had approximately three times the overall complication rate than those performed on smaller wounds [41]. Various maximum dimensions of the skin island in paediatric patients have been described as follows: $5.0 \mathrm{~cm} \times 9.0 \mathrm{~cm}$ by Mahmood et al. [30], $12.0 \mathrm{~cm} \times 8.0 \mathrm{~cm}$ by Liu et al. [32], $8.0 \mathrm{~cm} \times 10.0$ $\mathrm{cm}$ by Koladi et al. [28], and $15.0 \mathrm{~cm} \times 13.0 \mathrm{~cm}$ by Zheng et al. [33]. In their studies, the dimension of the skin island in the majority of the flaps was less than 80.0 $\mathrm{cm}^{2}$. Zheng et al. reported only seven flaps with a dimension of the skin island $\geq 100.0 \mathrm{~cm}^{2}$ [33]. In our study, the average dimension of the skin island was approximately $80.8 \mathrm{~cm}^{2}$, and the maximum dimension was $15.0 \mathrm{~cm} \times 11.0 \mathrm{~cm}$. The dimension of the skin island was $80.0 \mathrm{~cm}^{2}$ or more in approximately half of the patients, and the dimension was $100.0 \mathrm{~cm}^{2}$ or more in a quarter of the patients. No flaps had partial necrosis when the dimension of the skin island was $<80.0 \mathrm{~cm}^{2}$, and the partial necrosis rate in the flaps with a dimension of the skin island $\geq 100.0 \mathrm{~cm}^{2}$ was significantly higher. The results suggested that the flap could help repair relatively larger defects, the DBSF flap with a dimension of the skin island $<80.0 \mathrm{~cm}^{2}$ was safer and more reliable, and the possibility of partial necrosis increased significantly if the dimension of the skin island was $\geq 100.0 \mathrm{~cm}^{2}$.

In our study, the age of each paediatric patient was 12 or less 12 years old, and the average age of the paediatric patients was 6.9 years. In the paediatric population, the perforators originating from the peroneal artery are smaller in absolute size than those in adults [36]. Serletti et al. found vessel patterns in adolescent patients (ages between 13 and 17 years), such as size, wall characteristics, and spasm tendency, similar to those seen in adults, and the operative methods did not change compared with those in adults [1]. Herein, adolescent patients between 13 and 17 years of age were excluded from the study. In addition, trauma was the main aetiology leading to these defects $(93.2 \%, 82 / 88)$. Motorcycle spoke injury and traffic accidents made up the majority of trauma cases in the study. The degree and complexity of injuries in paediatric patients are usually more serious $[5,31,32]$. The reasons might be parent negligence and the fact that the paediatric population is more likely to play on the street alone and have less vigilance to risk factors around them and that skin soft tissue has poor damage resistance ability [32].

The indications for and advantages of DBSF flaps have been described in detail in previous studies [25, $26,28,33,34,42]$. In addition, another advantage is that injuries of adjacent structures can be synchronously reconstructed during DBSF flap surgery [31]. DBSF flaps have gained acceptance because of their advantages, but the major shortcoming of these flaps is the unsightly scar over the posterior calf, and some 
patients need debulking procedures to achieve aesthetics and comfort when wearing shoes. In the study, the donor site was not closed primarily because the subcutaneous fat in paediatric patients is thicker and the flaps were larger. Because subcutaneous fat in paediatric patients is thicker, the skin island of DBSF flaps should be designed to be approximately $1.0 \mathrm{~cm}$ or $1.5 \mathrm{~cm}$ larger in the periphery than the form of the defect. Otherwise, there will be tension in the stitching with the edge of the recipient site. Once tension is formed, the flap viability is affected.

During the follow-up period, the higher proportion of obvious scars in the donor site, the lower proportion of ulcerations in the flaps, and the few paediatric patients who required debulking procedures might have been related to the thicker subcutaneous fat and rapid body growth. The lower proportion of ulceration might be associated with the lighter body weight of paediatric patients and the partial sensory recovery [32]. The results of gait analysis and reconstruction outcomes were encouraging. This might be related to the higher adaptability in paediatric patients.

The main purposes for the reconstruction of defects in the lower leg, foot, and ankle are to restore lower extremity function, avoid amputation, control infection, and regain confidence by patients. Paediatric patients, as a special group, need to be specifically considered. Once an injury occurs in paediatric patients, it will affect them throughout their lifetime. $\mathrm{Hu}$ et al. assessed the psychosocial impact of multiple operations for paediatric patients, and the results indicated that the psychosocial functioning of paediatric patients was impaired if they underwent repetitive procedures [43]. Postoperative physical and psychological rehabilitation is beneficial to the normal development and healthy growth of paediatric patients [32]. In addition, paediatric patients grow up under the supervision of their parents. Hence, it is important for doctors to communicate with parents about the condition of paediatric patients.

The sample size of the study was considerable, and to the best of our knowledge, the study also has the largest sample size focusing on the application of DBSF flaps in paediatric patients at present. Because the study was a retrospective clinical study, a randomised controlled trial was not possible.

\section{Conclusions}

The major shortcoming of distally based sural fasciocutaneous flaps is the unsightly scar over the posterior calf; however, these flaps represent an ideal option for paediatric patients to cover defects in the extremities because of their reliability, simplicity, and encouraging functional results. Partial necrosis of the flap will increase significantly when the top edge of the flap is located in the 9th zone, when the LWR of the flap is $\geq 5: 1$, or when the dimension of the skin island is $\geq 100.0 \mathrm{~cm}^{2}$. Flaps with a skin-island width $<7.0 \mathrm{~cm}$ or a dimension of the skin island $<80 \mathrm{~cm}^{2}$ are relatively safe and reliable. The outcomes will be helpful for flap planning to avoid partial necrosis in paediatric patients.

\section{Abbreviations}

DBSF: Distally based sural fasciocutaneous; DM: Diabetes mellitus; PVD: Peripheral vascular disease; LWR: Length-to-width ratio; OR: Odds ratio; Cl: Confidential interval

\section{Acknowledgements}

Not applicable.

\section{Authors' contributions}

All authors have made substantial contributions. ZBL contributed to the study design and data analysis and wrote the manuscript. JDN, GHL, and JWW contributed to the study design and critically appraised the manuscript. LHL and PP collected the data and performed the literature search. ZGD contributed to the study design and data analysis and was the chief investigator of the study. All authors contributed to data interpretation and commented on previous versions of the manuscript. All authors read and approved the final manuscript.

\section{Funding}

National Natural Science Foundation of China, Grant/Award Number: 81672188; Health and Family Planning Commission of Hunan Province, Grant/Award Number: B20180313.

Availability of data and materials

Not applicable

\section{Ethics approval and consent to participate}

This study was approved by the medical ethics committee of the Second Xiangya Hospital Central South University. All patients involved in this study gave informed written consent to participate.

\section{Consent for publication}

Written informed consent was obtained from all participants.

\section{Competing interests}

The authors declare that they have no competing interests.

\section{Author details}

'Department of Spine Surgery, The Second Xiangya Hospital, Central South University, Changsha 410011, People's Republic of China. ${ }^{2}$ Department of Orthopaedics, The Second Xiangya Hospital, Central South University,

Changsha 410011, People's Republic of China.

Received: 11 November 2020 Accepted: 4 January 2021

Published online: 13 January 2021

\section{References}

1. Serletti JM, Schingo VA Jr, Deuber MA, Carras AJ, Herrera HR, Reale VF. Free tissue transfer in pediatric patients. Ann Plast Surg. 1996;36:561-8.

2. Hamdi MF, Khlifi A. Lateral supramalleolar flap for coverage of ankle and foot defects in children. J Foot Ankle Surg. 2012;51:106-9.

3. Luo Z, Qing L, Zhou Z, Wu P, Yu F, Tang J. Reconstruction of large soft tissue defects of the extremities in children using the kiss deep inferior epigastric artery perforator flap to achieve primary closure of donor site. Ann Plast Surg. 2019;82:64-70.

4. Eubanks RD, Bowker HD, Al-Mufarrej F. Innervated dorsalis pedis advancement flap for burn foot contractures. J Burn Care Res. 2020;41:466-71.

5. He XQ, Zhu YL, Duan JZ, Xu YQ, Jin T, Yang J, Mei LB, Wang Y. Post traumatic reconstruction of the pediatric heel and achilles tendon: a review 
of pedicle flap options in 31 motorcycle spoke trauma patients. Ann Plast Surg. 2016;77:653-61.

6. Lin CH, Mardini S, Wei FC, Lin YT, Chen CT. Free flap reconstruction of foot and ankle defects in pediatric patients: long-term outcome in 91 cases. Plast Reconstr Surg. 2006;117:2478-87.

7. Kapadia A, Cheruvu VR, John JR, Tripathy S, Sharma RK. Reconstruction in pediatric orthopedic trauma: the role of primary cross leg flap cover. J Pediatr Orthop B. 2017;26:172-8.

8. Tang J, Fang T, Song D, Liang J, Yu F, Wang C. Free deep inferior epigastric artery perforator flap for reconstruction of soft-tissue defects in extremities of children. Microsurgery. 2013;33:612-9.

9. Özalp B, Aydınol M. Perforator-based propeller flaps for leg reconstruction in pediatric patients. J Plast Reconstr Aesthet Surg. 2016;69:e205-11.

10. Zhang Y, Liu Y, Tian S, Song L, Peng A. Step-advanced rectangular flap: a novel technique for the reconstruction of soft-tissue defects overlying the Achilles tendon in children (an observational study). Medicine (Baltimore). 2019;98(41):e17268.

11. Zhu YL, Wang Y, He XQ, Zhu M, Li FB, Xu YQ. Foot and ankle reconstruction: an experience on the use of 14 different flaps in 226 cases. Microsurgery. 2013;33:600-4.

12. Gözü A, Ozyiğit T, Ozsoy Z. Use of distally pedicled sural fasciocutaneous cross-leg flap in severe foot and ankle trauma: a safe alternative to microsurgery in very young children. Ann Plast Surg. 2005;55:374-7.

13. Qing L, Wu P, Zhou Z, Yu F, Tang M, Tang J. A design for the dual skin paddle circumflex scapular artery perforator flap for the reconstruction of complex soft-tissue defects in children: anatomical study and clinical applications. Ann Plast Surg. 2019;83:439-46.

14. Acar MA, Güleç A, Aydin BK, Erkoçak ÖF, Yilmaz G, Şenaran H. Reconstruction of foot and ankle defects with a free anterolateral thigh flap in pediatric patients. J Reconstr Microsurg. 2015;31:225-32.

15. Upton J, Guo L. Pediatric free tissue transfer: a 29-year experience with 433 transfers. Plast Reconstr Surg. 2008;121:1725-37.

16. Duteille F, Lim A, Dautel G. Free flap coverage of upper and lower limb tissue defects in children: a series of 22 patients. Ann Plast Surg. 2003;50: 344-9.

17. Masquelet AC, Romana MC, Wolf G. Skin island flaps supplied by the vascular axis of the sensitive superficial nerves: anatomic study and clinical experience in the leg. Plast Reconstr Surg. 1992;89:1115-21.

18. Yang D, Morris SF. Reversed sural island flap supplied by the lower septocutaneous perforator of the peroneal artery. Ann Plast Surg. 2002:49:375-8.

19. Akhtar S, Hameed A. Versatility of the sural fasciocutaneous flap in the coverage of lower third leg and hind foot defects. J Plast Reconstr Aesthet Surg. 2006;59:839-45.

20. Daar DA, Abdou SA, David JA, Kirby DJ, Wilson SC, Saadeh PB. Revisiting the reverse sural artery flap in distal lower extremity reconstruction: a systematic review and risk analysis. Ann Plast Surg. 2020;84:463-70.

21. Roberts HJ, DeSilva GL. Can sural fasciocutaneous flaps be effective in patients older than 65? Clin Orthop Relat Res. 2020:478:734-8.

22. Perumal R, Bhowmick K, Reka K, Livingston A, Boopalan PRJVC, Jepegnanam TS. Comparison of reverse sural artery flap healing for traumatic injuries above and below the ankle joint. J Foot Ankle Surg. 2019;58:306-11.

23. As'adi K, Salehi SH, Shoar S. Early reconstruction of distal leg and foot in acute high-voltage electrical burn: does location of pedicle in the zone of injury affect the outcome of distally based sural flap? Ann Plast Surg. 2017; 78:41-5.

24. Lee HI, Ha SH, Yu SO, Park MJ, Chae SH, Lee GJ. Reverse sural artery island flap with skin extension along the pedicle. J Foot Ankle Surg. 2016;55:470-5.

25. Follmar KE, Baccarani A, Baumeister SP, Levin LS, Erdmann D. The distally based sural flap. Plast Reconstr Surg. 2007;119:138e-48e.

26. Baumeister SP, Spierer R, Erdmann D, Sweis R, Levin LS, Germann GK. A realistic complication analysis of 70 sural artery flaps in a multimorbid patient group. Plast Reconstr Surg. 2003;112:129-40.

27. Oğün TC, Arazi M, Ozdemir M, Sarlak A. One-stage treatment of open tibial fracture in a child using a distally based sural artery flap: a case report. J Orthop Trauma. 2001;15:578-80.

28. Koladi J, Gang RK, Hamza AA, George A, Bang RL, Rajacic N. Versatility of the distally based superficial sural flap for reconstruction of lower leg and foot in children. J Pediatr Orthop. 2003;2:194-8

29. Vergara-Amador E. Distally-based superficial sural neurocutaneous flap for reconstruction of the ankle and foot in children. J Plast Reconstr Aesthet Surg. 2009;62:1087-93.
30. Mahmood F, Mehrose MY, Tasneem S, Mahmood N, Raza A. Distally based superficial sural artery flap for foot and ankle reconstruction in children. J Ayub Med Coll Abbottabad. 2011;23:40-2.

31. Wei JW, Ni JD, Dong ZG, Liu LH, Luo ZB, Zheng L, He AY. Distally based perforator-plus sural fasciocutaneous flap for reconstruction of complex soft tissue defects caused by motorcycle spoke injury in children. J Trauma Acute Care Surg. 2012;73:1024-7.

32. Liu L, Liu Y, Zou L, Li Z, Cao X, Cai J. The distally based superficial sural flap for reconstruction of the foot and ankle in pediatric patients. J Reconstr Microsurg. 2013;29:199-204.

33. Zheng H, Liu J, Dai X, Schilling AF. The distally based sural flap for the reconstruction of ankle and foot defects in pediatric patients. Ann Plast Surg. 2016;77:97-101.

34. Grandjean A, Romana C, Fitoussi F. Distally based sural flap for ankle and foot coverage in children. Orthop Traumatol Surg Res. 2016;102:111-6.

35. Wei JW, Dong ZG, Ni JD, Liu LH, Luo SH, Luo ZB, Zheng L, He AY. Influence of flap factors on partial necrosis of reverse sural artery flap: a study of 179 consecutive flaps. J Trauma Acute Care Surg. 2012;72:744-50.

36. Wei JW, Ni JD, Dong ZG, Liu LH, Luo ZB, Zheng L. Distally based perforatorplus sural fasciocutaneous flap for soft-tissue reconstruction of the distal lower leg, ankle, and foot: comparison between pediatric and adult patients. J Reconstr Microsurg. 2014;30:249-54.

37. Dong ZG, Wei JW, Ni JD, Liu LH, Luo ZB, Zheng L, He AY. Anterograderetrograde method for harvest of distally based sural fasciocutaneous flap: report of results from 154 patients. Microsurgery. 2012;32:611-6.

38. Peng P, Luo Z, Lv G, Ni J, Wei J, Dong Z. Distally based peroneal artery perforator-plus fasciocutaneous flap in the reconstruction of soft tissue defects over the distal forefoot: a retrospectively analyzed clinical trial. J Orthop Surg Res. 2020;15:487.

39. Boyden EM, Kitaoka HB, Cahalan TD, An KN. Late versus early repair of Achilles tendon rupture. Clinical and biomechanical evaluation. Clin Orthop Relat Res. 1995;317:150-8.

40. de Blacam C, Colakoglu S, Ogunleye AA, Nguyen JT, Ibrahim AM, Lin SJ, Kim PS, Lee BT. Risk factors associated with complications in lower-extremity reconstruction with the distally based sural flap: a systematic review and pooled analysis. J Plast Reconstr Aesthet Surg. 2014;67:607-16.

41. Shea P, O'Hara NN, Spraque SA, Bhandari M, Petrisor BA, Jeray KJ, Zhan M, Slobogean GP. Pensy RA; Fluid lavage in open wounds investigators. wound surface area as a risk factor for flap complications among patients with open fractures. Plast Reconstr Surg. 2018;142:228-36.

42. Luo Z, Lv G, Wei J, Ni J, Liu L, Peng P, Dong Z. Comparison between distally based peroneal and posterior tibial artery perforator-plus fasciocutaneous flap for reconstruction of the lower extremity. Burns. 2020;46:225-33.

43. Hu AC, Bertrand AA, Dang BN, Chan CH, Lee JC. The effect of multiple surgeries on psychosocial outcomes in pediatric patients: a scoping review. Ann Plast Surg. 2020;85:574-83.

\section{Publisher's Note}

Springer Nature remains neutral with regard to jurisdictional claims in published maps and institutional affiliations.

Ready to submit your research? Choose BMC and benefit from:

- fast, convenient online submission

- thorough peer review by experienced researchers in your field

- rapid publication on acceptance

- support for research data, including large and complex data types

- gold Open Access which fosters wider collaboration and increased citations

- maximum visibility for your research: over $100 \mathrm{M}$ website views per year

At $\mathrm{BMC}$, research is always in progress.

Learn more biomedcentral.com/submission 